\title{
Study on level of control of bronchial asthma in a peripheral paediatric unit in Sri Lanka
}

\author{
D C N Amarasiri ${ }^{1}$, Deepthi Samarage ${ }^{2}$, Guwani Liyanage 2 , P M R S N Pallemulla ${ }^{3}$, P K B Mahesh ${ }^{4}$
}

Sri Lanka Journal of Child Health, 2014; 43(4): 208-211

\begin{abstract}
Objectives: To describe the level of control of asthma and the factors associated with poorly controlled asthma in children registered at the Paediatric Clinic at Base Hospital, Kanthale in the Trincomalee District of the Eastern Province of Sri Lanka and to identify co-morbid factors associated with poorly controlled asthma..
\end{abstract}

Method: It was a prospective cross sectional study conducted in the Paediatric Clinic at Base Hospital Kanthale. Data was collected using an interviewer administered questionnaire from 88 physician diagnosed asthma patients. Asthma Therapy Assessment Questionnaire (ATAQ) was used to assess asthma control.

Results: Majority of patients (75\%) had poorly controlled asthma. Statistically significant associations were noted between poorly controlled asthma and incorrect inhaler technique $(\mathrm{p}<0.001)$, poor compliance of steroid inhalers $(\mathrm{p}<0.001)$, allergic rhinitis $(p<0.01)$, clinical evidence of gastrooesophageal reflux disease $(p<0.01)$ and exposure to second-hand smoke at home $(\mathrm{p}<0.05)$.

Conclusions: In our study $75 \%$ had poorly controlled bronchial asthma. Poor control of bronchial asthma was significantly associated with incorrect inhaler technique, poor compliance to steroid inhaler, allergic rhinitis, gastro-oesophageal reflux disease and exposure to cigarette smoke at home.

(Key words: Bronchial asthma; level of control; ATAQ questionnaire)

${ }^{1}$ Acting Consultant Paediatrician, Base Hospital, Kanthale, ${ }^{2}$ Senior Lecturer, Department of Paediatrics, University of Sri Jayawardenapura, ${ }^{3}$ Specialty Registrar in Paediatrics, Calderdale Hospital, United Kingdom, ${ }^{4}$ Registrar in Community Medicine, Department of Community Medicine, University of Colombo

(Received on 10 March 2014: Accepted after revision on 25 April 2014)

\section{Introduction}

International Study of Asthma and Allergies in Childhood (ISAAC) reported a global prevalence of wheeze of $11.8 \%$ for children aged 6-7 years and $13.8 \%$ for children aged $13-14$ years, although there were up to 15 -fold differences in prevalence rates between countries ${ }^{1}$. Childhood asthma causes considerable morbidity, especially during periods when it is insufficiently controlled. This is reflected in frequent symptoms, high rates of emergency admissions and hospitalization, as well as absence from school and it is a significant burden for the whole family of an asthmatic child ${ }^{1}$.

International and National Guidelines have been introduced for physician guidance on how to provide optimal asthma care ${ }^{1}$. Factors associated with the control of asthma, to the best of our knowledge, have never previously been studied in a very rural population in Sri Lanka.

\section{Objectives}

- To describe the level of control of asthma in children registered at the paediatric clinic at Base Hospital, Kanthale in the Trincomalee District of the Eastern Province of Sri Lanka.

- To elucidate factors associated with insufficient asthma control

- To identify co-morbid factors associated with poorly controlled asthma.

\section{Method}

A descriptive cross-sectional study was carried out in Base Hospital, Kanthale in the Eastern Province of Sri Lanka from the $2^{\text {nd }}$ October 2013 to $2^{\text {nd }}$ January 2014. Children with asthma on steroid inhalers were recruited into the study. Children with chronic illness were excluded from the study. 
A pre-tested questionnaire collected demographic data, details of medications, environmental risk factors and co-morbid conditions related to asthma. Asthma control was measured using the Asthma Therapy Assessment Questionnaire (ATAQ). It was translated into Sinhala and Tamil languages and then back translated to English to confirm accuracy. ATAQ assesses the control over the previous 4 weeks. The level of control was determined according to a scoring system. Those who scored 0 were considered as well controlled and those who scored one or more were considered as poorly controlled. The poorly controlled category was further subdivided into two groups (score between 1 to 3 and score equal to or more than 4).

A single trained investigator interviewed both parents of all eligible children. All parents were provided leaflets containing details of the study and written consent was obtained prior to data collection. Strict anonymity and confidentiality were maintained. Ethical clearance was obtained from the Ethical Review Committee of the University of Rajarata. Data was analysed using SPSS soft-ware.

\section{Results}

There were 95 diagnosed asthma patients registered at the Paediatric Clinic in Base Hospital-Kanthale of whom 91 were on steroid inhalers. Two patients were excluded as they had other chronic illnesses. Out of 89 eligible patients one did not attend the study. Thus the total number of participants was 88 (38 female and 50 male). Age distribution of study population was from 5-12 years with a mean age of 7.8 years.

The children were divided into 3 groups according to the score given by the ATAQ questionnaire. Those who scored zero were categorized as fully controlled asthma disease. There were 22 fully controlled asthma patients (4 girls, 8 boys). Twenty seven children (6 girls, 21 boys) scored 1-3 and 39 children (17 girls, 22 boys) scored more than 4 .

Of the 88 mothers, 76 had studied up to Ordinary Level (O/L) and 12 above O/L. In the well-controlled group 17 mothers had studied up to $\mathrm{O} / \mathrm{L}$ and 5 above $\mathrm{O} / \mathrm{L}$. In the poorly controlled subgroup with a score of 4 or more, 34 mothers had studied up to $\mathrm{O} / \mathrm{L}$ and 5 above $\mathrm{O} / \mathrm{L} \quad(\mathrm{P}=0.15)$. No one was completely illiterate. Of the 88 fathers, 77 fathers had studied up to $\mathrm{O} / \mathrm{L}$ and 11 above $\mathrm{O} / \mathrm{L}$. In the well-controlled group18 fathers had had studied up to $\mathrm{O} / \mathrm{L}$ and 4 above $\mathrm{O} / \mathrm{L}$. In the poorly controlled subgroup with a score of 4 or more, 32 fathers had studied up to $\mathrm{O} / \mathrm{L}$ and 7 above $\mathrm{O} / \mathrm{L}(\mathrm{P}=0.32)$. None were completely illiterate. Thus there was no significant association between mothers' or fathers' education and poor control of asthma.

When we consider the duration of the illness 45 $(51.1 \%)$ children were diagnosed as having asthma for 2 to 5 years. In the well-controlled group $11(50 \%)$ children were diagnosed as having asthma for 2 to 5 years. In the poorly controlled subgroup with a score of 4 or more, $18(51 \%)$ were diagnosed as having asthma for 2 to 5 years. There was no statistically significant difference between duration of illness and the severity of score.

In the well-controlled group, none of the patients had poor inhaler technique. In the poorly controlled group 38 (57.5\%) patients had incorrect inhaler technique (P $<0.001)$. All the patients in the well-controlled group were using steroid inhalers 7 days per week. Thirty six $(54.5 \%)$ patients in the poorly controlled group used inhalers less than 7 days per week $(\mathrm{P}<0.001)$.

Environmental factors associated with asthma control

In the well-controlled group only $2(9 \%)$ children had smokers at home. In the poorly controlled group, 20 $(30.3 \%)$ children had smokers at home $(\mathrm{P}<0.05)$

In the well-controlled group $9(40 \%)$ patients had pets at home compared to $34(51.5 \%)$ in the poorly controlled group $(\mathrm{P}=0.389)$. In the well-controlled group 10 (45\%) patients had soft toys at home compared to $32(48.4 \%)$ in the poorly controlled group $(\mathrm{P}=0.805)$. House condition was inadequate in $12(54 \%)$ patients in the well-controlled group compared to $38(57.5 \%)$ in the poorly controlled group $(\mathrm{P}=0.804)$. In the well-controlled group environmental pollution around house occurred in 5 $(22 \%)$ patients compared to $19(28.7 \%)$ in the poorly controlled group $(\mathrm{P}=0.580)$. Frequency of bed linen washing was not adequate in $1(4.6 \%)$ patient in the well-controlled group compared to $6(09 \%)$ in the poorly controlled group $(\mathrm{P}=0.495)$.

\section{Co-morbid conditions in poorly controlled asthma}

In the well-controlled group $6(27 \%)$ patients had atopy compared to $14(21.2 \%)$ in the poorly controlled group $(\mathrm{P}=0.557)$. None of the wellcontrolled group had recurrent sinusitis compared to $8(12.1 \%)$ in the poorly controlled group $(\mathrm{P}=0.087)$. Two (9\%) patients had recurrent upper respiratory tract infections in the well-controlled group compared to $16(24.2 \%)$ in the poorly controlled group $(\mathrm{P}=0.127)$. 
In the well-controlled group $10(45 \%)$ patients had allergic rhinitis compared to $53(77 \%)$ in the poorly controlled group $(\mathrm{P}=0.002)$. None of the wellcontrolled group patients had GORD compared to 15 $(22.7 \%)$ in the poorly controlled group $(\mathrm{P}=0.014)$. Level of control of asthma
Level of asthma control was assessed with ATAQ. Twenty two (25\%) were well controlled and 66 (75\%) were poorly controlled. Overall $44.3 \%$ had ATAQ score equal to or more than 4 , indicating very poor control. Detailed analysis of each question of ATAQ among the poorly controlled children is shown in table 1 .

Table 1: Analysis of ATAQ in poorly controlled group $(n==66)$

\begin{tabular}{|l|r|r|}
\hline \multicolumn{1}{|c|}{ Component } & \multicolumn{2}{c|}{ Response } \\
\cline { 2 - 3 } & \multicolumn{1}{c|}{ No } & \multicolumn{1}{c|}{ Yes } \\
\hline Wheezing or Difficulty in breathing in exercise & $20(30.3 \%)$ & $46(69.7 \%))$ \\
\hline Wheezing or Difficulty in breathing during day when not exercising & $25(37.9 \%)$ & $41(62.1 \%)$ \\
\hline Wake up at night with wheezing or difficulty breathing & $19(28.8 \%)$ & $47(71.2 \%)$ \\
\hline Miss days of school because of her /his asthma & $31(47 \%)$ & $35(53 \%)$ \\
\hline Miss any daily activities because of her /his asthma & $44(66.7 \%)$ & $22(33.3 \%)$ \\
\hline Use an inhaler or a nebulizer for quick relief from asthma symptom & $32(48.4 \%)$ & $34(51.5 \%)$ \\
\hline Believe your child's asthma was well controlled in the past 4 weeks & $56(84.8 \%)$ & $10(15.1 \%)$ \\
\hline
\end{tabular}

\section{Discussion}

Only a small percentage of children with asthma reach the goals of good asthma control set out by Global Initiative for Asthma (GINA) ${ }^{2}$ Guidelines.

Factors influencing asthma control are complex. Previous studies have consistently identified that individual factors such as genetics, smoking inside the home, poor design of inhaler device, improper medication compliance as well as family and environmental factors such as pets in the home, air pollution and pollen exposure are important determinants of poorly controlled asthma ${ }^{2}$.

Recently, more attention has been focused on the impact of parental factors on asthma outcomes. Parental health literacy of children with asthma, for example, is one such factor that might directly contribute to optimal asthma care of their children. Low health literacy levels could influence parents' understanding of asthma aetiology, capability of engaging in the decision-making process with providers and compliance with the treatment plan. However, in our study, literacy level did not show any impact on the asthma control.

There could be parental factors that are not related to literacy level affecting asthma control. Fear of sideeffects of long-term medications, myths such as developing addiction to inhaled steroids and poor understanding of the natural history of the disease are some of the factors that needs to be investigated.
In this study, a majority $(n=62,70.4 \%)$ of the patients were using metered-dose inhalers (MDI) with spacers. Poor inhaler technique as a reason for poor control is highlighted in this study. However, device selection should be based on a patient's acceptance, ability and preferences ${ }^{3}$. Importantly, educating them on correct technique repeatedly at clinic visits should be part of routine care.

Adherence to treatment is an important component of asthma management and control and this has been reiterated in our study. Non-adherence should be considered in all children with poorly controlled asthma. Adolescents, children from chaotic families, and children from socially disadvantaged groups are at increased risk of non-adherence. Treatment plans should be developed collaboratively and it is important to explore the patient's concerns and prejudices.

Electronic monitoring devices (EMDs) have been proposed as the Gold Standard for measuring adherence ${ }^{4}$. EMDs record a time stamp which can be downloaded and compared with the prescribed regimen. EMDs do have limitations, most importantly they are expensive and some devices have been prone to electrical malfunction ${ }^{5}$. In the future, EMDs are likely to play a greater role as an aid to increase compliance.

Household cigarette smoke exposure was a significant factor associated with poor control. This is comparable to other studies that found that children exposed to tobacco smoke were more likely to be subjected to increased asthma exacerbations and 
negative effects on lung function ${ }^{6,7}$. Therefore, patients \& parents need to be educated in reducing exposure to tobacco smoke. Avoidance of smoke exposure should be a relatively simple management strategy and if cessation is immediately not available, then even advice to smoke only outside the home would probably help.

Asthma appears to be more prevalent among people with gastro-oesophageal reflux (GORD) ${ }^{8}$. In our study GORD was also more prevalent among children with poorly controlled asthma. A trial of acid suppression therapy may be worthwhile if GORD is suspected, but treatment for reflux does not predictably improve asthma control ${ }^{9}$.

It has been shown that allergic rhinitis has a major impact on asthma and that treatment of allergic rhinitis helps to improve asthma control ${ }^{10}$. In our study too we found that poor control of bronchial asthma was significantly associated with allergic rhinitis $(\mathrm{p}<0.01)$.

\section{Conclusions}

- In our study $75 \%$ had poorly controlled bronchial asthma.

- Poor control of bronchial asthma was significantly associated with incorrect inhaler technique, poor compliance to steroid inhaler, allergic rhinitis, gastro-oesophageal reflux disease and exposure to cigarette smoke at home.

\section{References}

1. Gustafsson PM, Watson L, Davis KJ, Rabe KF. Poor asthma control in children : Evidence from epidemiological surveys and implications for clinical practice. Clinical Practice 2006; 3:321-4. http://dx.doi.org/10.1111/j.13685031.2006.0079 $\underline{8 . x}$

2. Gandi PK, Kenzik KM, Thompson LA, Dewalt DA, Revicki DA, Shenkman EA, et al. Exploring factors influencing asthma control and asthma- specific health -related quality of life among children. Respiratory Research 2013: 14:26

http://dx.doi.org/10.1186/1465-9921-14-26

3. Lenney J, Innes JA, Crompton GK. Inappropriate inhaler use: assessment of use and patient preference of seven inhalation devices. EDICI. Respiratory Medicine 2000; 94(5): 496500.

http://dx.doi.org/10.1053/rmed.1999.0767

4. Cramer JA. Microelectronic systems for monitoring and enhancing patient compliance with medication regimens. Drugs 1995; 49(3):321-7. http://dx.doi.org/10.2165/00003495-199549030$\underline{00001}$

5. Riekert KA, Rand CS. Electronic monitoring of medication adherence: when is high-tech best? Journal of Clinical Psychology in Medical Settings 2002; 9(1): 25-34. http://dx.doi.org/10.1023/A:1014131928789

6. Burr ML, Anderson HR, Austin JB, Harkins LS, Kaur B, Strachan DP, et al. Respiratory symptoms and home environment in children: A national survey. Thorax 1999; 54(1):27-32. http://dx.doi.org/10.1136/thx.54.1.27

7. Morkjaroenpong V, Rand CS, Butz AM, Huss K, Eggleston P, Malveaux FJ, et al. Environmental tobacco smoke exposure and nocturnal symptoms among inner-city children with asthma. Journal of Allergy and Clinical Immunology 2002; 110(1):147-53. http://dx.doi.org/10.1067/mai.2002.125832

8. Demeter P, Pap A. The relationship between gastro-esophageal reflux disease and obstructive sleep apnea. Journal of Gastroenterology 2004; 39(9): 815-20.

http://dx.doi.org/10.1007/s00535-004-1416-8

9. Gibson PG, Henry RL, Coughlan JL. Gastrooesophageal reflux treatment for asthma in adults and children. Cochrane Database of Systemic Reviews 2003, CD001496. Available from: http://www.ncbi.nlm.nih.gov/pubmed/12804410[ Accessed on 28th January 2014]

10. De Groot EP, Nijkap A, Dulverman EJ, Brand PLP. Allergic rhinitis is associated with poor asthma control in children with asthma. Thorax 2012; 67(7):582-7. http://dx.doi.org/10.1136/thoraxjnl-2011-201168 